Working Paper/Document de travail 2015-26

\title{
On the Welfare Cost of Rare Housing Disasters
}

by Shaofeng Xu 


\title{
Bank of Canada Working Paper 2015-26
}

July 2015

\section{On the Welfare Cost of Rare Housing Disasters}

\author{
by \\ Shaofeng Xu \\ Canadian Economic Analysis Department \\ Bank of Canada \\ Ottawa, Ontario, Canada K1A 0G9 \\ sxu@bankofcanada.ca
}

Bank of Canada working papers are theoretical or empirical works-in-progress on subjects in economics and finance. The views expressed in this paper are those of the author. No responsibility for them should be attributed to the Bank of Canada. 


\section{Acknowledgements}

I thank Shutao Cao, Jim MacGee, Yaz Terajima, Alexander Ueberfeldt, and seminar participants at the Bank of Canada, Carleton University, Asian Meeting of the Econometric Society (2014), Canadian Economics Association Conference (2014), and European Meeting of the Econometric Society (2014) for helpful comments. Any errors are solely my responsibility. 


\begin{abstract}
This paper examines the welfare cost of rare housing disasters characterized by large drops in house prices. I construct an overlapping generations general equilibrium model with recursive preferences and housing disaster shocks. The likelihood and magnitude of housing disasters are inferred from historic housing market experiences in the OECD. The model shows that despite the rarity of housing disasters, Canadian households would willingly give up 5 percent of their non-housing consumption each year to eliminate the housing disaster risk. The evaluation of this risk, however, varies considerably across age groups, with a welfare cost as high as 10 percent of annual non-housing consumption for the old, but near zero for the young. This asymmetry stems from the fact that, compared to the old, younger households suffer less from house price declines in disaster periods, due to smaller holdings of housing assets, and benefit from lower house prices in normal periods, due to the negative price effect of disaster risk.

JEL classification: E21, E44, G11, R21

Bank classification: Housing; Asset pricing; Economic models
\end{abstract}

\title{
Résumé
}

L'étude chiffre la perte de bien-être causée par les fortes chutes de prix des logements (phénomène rare des catastrophes sur le marché du logement). L'étude s'appuie sur un modèle d'équilibre général à générations imbriquées avec préférences récursives et chocs créés par l'effondrement des prix des logements. La probabilité et l'ampleur de telles catastrophes sont calculées au moyen des prix observés sur le marché du logement dans les pays de l'OCDE. Les résultats montrent que les ménages canadiens sont prêts à sacrifier chaque année $5 \%$ de leurs dépenses de consommation hors logement afin d'éviter la matérialisation d'un risque d'effondrement des prix. Ce risque est évalué très différemment selon le groupe d'âge, les ménages plus âgés estimant la perte résultante de bien-être à $10 \%$ de leurs dépenses de consommation annuelles hors logement, alors que les jeunes ménages la jugent quasi nulle. Cette asymétrie s'explique par le fait que les jeunes ménages souffrent moins que leurs aînés des conséquences des chutes de prix des logements survenues pendant une catastrophe, car leur patrimoine immobilier est moins important, et qu'ils bénéficient du recul des prix des logements en temps normal, en raison de l'effet dépréciateur induit par le risque de catastrophe.

Classification JEL : E21, E44, G11, R21

Classification de la Banque : Logement; Évaluation des actifs; Modèles économiques 


\section{Non-Technical Summary}

Since the early 2000s, house prices have increased significantly in Canada. This ongoing housing boom has become an important consideration for the conduct of monetary policy and financial regulation, since currently high levels of house prices are potentially increasing the risk of a large housing market correction, which could have an adverse effect on the economy. This paper investigates the likelihood and magnitude of housing market disasters, and the value of limiting this disaster risk for the Canadian economy. The study will be useful for both economic researchers and policy-makers to better understand the macroeconomic implications of this important market risk.

This paper estimates the unconditional probability and the size of housing market disasters using the cross-country housing market experiences of twenty OECD countries. I find that in a given OECD country, housing market disasters - defined as cumulative peak-to-trough declines in real house prices of 20 percent or more - occur with a probability of 3 percent every year, corresponding to about one disaster occurring every 34 years. A housing disaster on average lasts about 6.4 years, and house price declines range from 25 to 68 percent, with an average decline of 34 percent.

This paper quantifies the welfare impact of the housing disaster risk in an overlapping generations general equilibrium housing model. The analysis yields the following two main findings. First, despite their statistical rarity, the aggregate welfare cost of housing disasters is large, since Canadian households would willingly give up around 5 percent of their non-housing consumption each year to eliminate the housing disaster risk. The sizable welfare cost is due to the large wealth loss during the long-lasting recessions triggered by housing disasters. Second, the welfare evaluation of this risk varies considerably across age groups, with a welfare cost as high as 10 percent of annual nonhousing consumption for the old, but near zero for the young. This asymmetry stems from the fact that, compared to the old, younger households suffer less from house price declines in disaster periods, due to smaller holdings of housing assets, and benefit from being able to buy homes at the resulting lower house prices in normal periods. 


\section{Introduction}

Since the early 2000s, house prices have increased significantly in Canada, as shown in Figure 1. ${ }^{1}$ This ongoing housing boom has become an important consideration for the conduct of monetary policy and financial regulation, ${ }^{2}$ since currently high levels of house prices are potentially increasing the risk of a large housing market correction, which could have a devastating impact on the macroeconomy, as recently seen in the United States. This paper investigates the likelihood and magnitude of housing market disasters, defined as large drops in house prices, and the value of limiting this disaster risk for the Canadian economy. I find that although housing market disasters are rare events from a statistical perspective, their macroeconomic effects are so large that they have significant welfare implications.

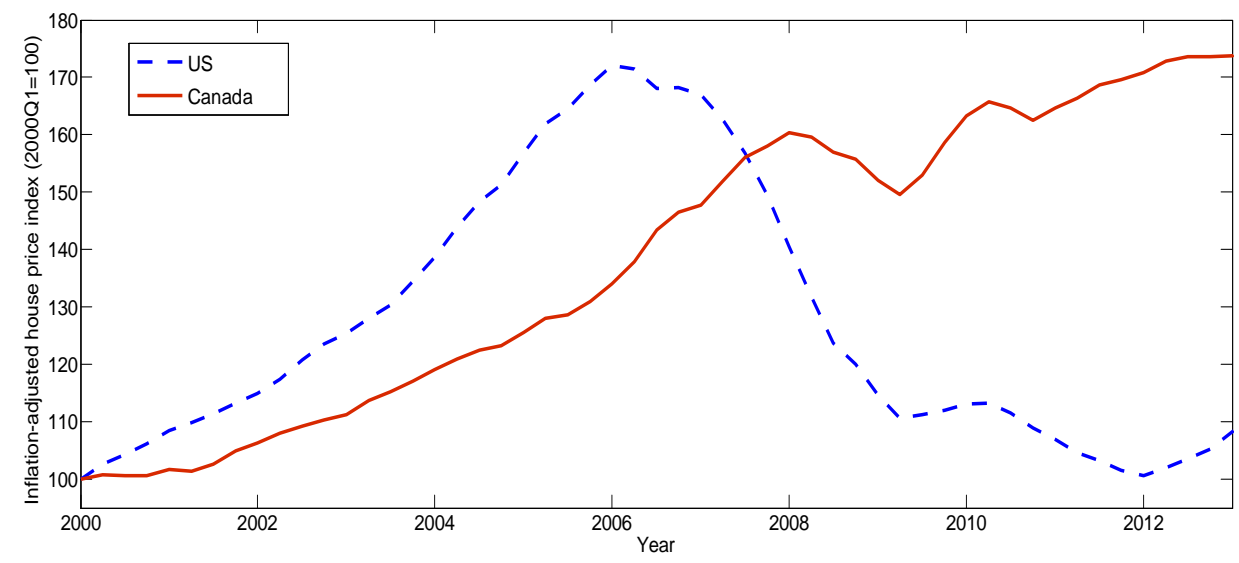

Figure 1: House price dynamics since 2000

Estimating the likelihood and magnitude of housing market disasters is difficult because those disasters are infrequent and house price series are short for many countries. To address the data scarcity problem, this paper adopts a method similar in spirit to Barro (2006) and uses cross-country housing market experiences in the OECD. ${ }^{3}$ In particular, I use house price data for twenty OECD countries reported in the property price statistics by the Bank for International Settlements with appropriate inflation adjustments. The paper defines a housing market disaster as cumulative peak-to-trough declines in real house prices of 20 percent or more. I find that in a given OECD country, housing market disasters occur with a probability of 3

\footnotetext{
${ }^{1}$ House prices for Canada and the United States are sourced from the Teranet-National Bank 11-City Composite House Price Index and the S\&P/Case-Shiller 20-City Composite Home Price Index, respectively.

${ }^{2}$ Canadian household debt, of which mortgage debt constitutes about 80 percent, has increased by more than 60 percent relative to disposable income during the period from 2000 to 2012.

${ }^{3}$ Barro (2006) estimates the statistical properties of income disasters in the OECD as those experienced in the Great Depression and two world wars. The author finds that an income disaster, defined as cumulative peak-to-trough declines in real per capita GDP of 15 percent or more, occurs with a probability of 2 percent per year with contractions in per capita GDP ranging between 15 and 64 percent.
} 
percent every year, corresponding to about one disaster every 34 years. ${ }^{4}$ A housing disaster on average lasts about 6.4 years, and house price declines range between 24 and 68 percent, with an average of about 34 percent.

To quantify both the aggregate and distributional welfare impact of this housing disaster risk, I construct an overlapping generations (OLG) general equilibrium model with recursive preferences and housing disaster shocks. The model economy is populated by overlapping generations of households, a representative firm and a government. There are two asset markets in the economy, namely, a financial market and a housing market. Households have Epstein-Zin preferences over consumption goods and housing services. The firm rents capital and employs labor to produce a numeraire good used for both consumption and investment. Households trade a one-period bond in the financial market and a durable housing asset in the housing market. Houses in the paper have the role of providing housing services, and serving as an asset and collateral. The economy is subject to aggregate housing disaster shocks modeled as housing depreciation shocks, similar to Iacoviello and Pavan (2013). These shocks can be interpreted as shocks to the quality of houses, which help generate large drops in house prices. I calibrate the parameters characterizing the properties of housing depreciation shocks to match the average historical house price decline during OECD house price crash episodes, and the rest of the benchmark model to match the recent Canadian data over the period 2000-2012. The welfare cost associated with the housing disaster risk is measured as the percentage change in the consumption of non-housing goods households would willingly give up in an otherwise-identical no-disaster economy in order to be as well off as living in the benchmark economy.

The main findings from the model are twofold. First, despite their rarity, the aggregate welfare cost of housing disasters is large, since Canadian households would be willing to give up around 5 percent of their non-housing consumption each year to eliminate the housing disaster risk. Compared to the no-disaster economy, the presence of this disaster risk has two opposite welfare effects on households. On the one hand, due to a wealth effect, a realized housing disaster leads to a long-lasting economic recession. The loss in housing wealth once a disaster occurs reduces the aggregate household savings and thus the capital supply. As a consequence, the interest rate goes up and the firm cuts back its investment, leading to declines in wages, output and consumption. On the other hand, due to a substitution effect, a non-trivial disaster probability results in risk-averse households' resource reallocation from the housing sector to the production sector in normal periods. This lowers both house prices and the interest rate, with declining borrowing costs leading to higher investment, output and consumption. However, due

\footnotetext{
${ }^{4}$ Different from Bauer (2014), who estimates the conditional likelihood of house price corrections of 10 percent or more, this paper focuses on the unconditional probability of housing market disasters as defined. With regard to the Canadian housing market, both papers find a low likelihood of experiencing large house price corrections, and the Bank of Canada has continued to forecast a constructive evolution of house prices (see the Bank of Canada's Financial System Review, December 2014).
} 
to diminishing marginal utility of consumption, the welfare gain from this resource reallocation in normal periods is dominated by the welfare loss from large recessions triggered by housing disasters, explaining why the society is willing to devote a sizable amount of resources to eliminating this disaster risk.

The second major finding is that the welfare evaluation of the housing disaster risk differs considerably in magnitude across age groups, with a welfare cost as high as 10 percent of annual non-housing consumption for the old, but near zero for the young. This asymmetry is mainly due to the hump-shaped profile of life-cycle housing consumption, with older households typically holding more housing assets than the young. In disaster periods, declines in house prices favor the young, who purchase houses at depressed prices, but hurt the old, who rely on house sales to finance non-housing consumption. In normal periods, younger households also benefit more than the old from purchasing houses at lower cost, thanks to the resource reallocation from the housing sector to the production sector as discussed above. Therefore, younger households are less averse to the presence of the housing disaster risk than the old.

This paper is mostly related to two strands of the literature. The first strand studies the implications of rare disaster risks for asset prices, business cycles and welfare. Examples include Rietz (1988), Barro (2006, 2009), Barro and Ursúa (2008), Gourio (2008, 2012), Gabaix (2012), Wachter (2013), Pindyck and Wang (2013), and Glover et al. (2014). My paper contributes to this literature by focusing on rare disasters related to housing markets with a careful examination of their welfare implications. The rare disaster hypothesis was first proposed by Rietz (1988), who argues that including a low-probability disaster state has a significant impact on asset pricing, and can resolve the well-known equity premium puzzle. However, partly due to the skepticism of the likelihood and sizes of disaster events, this hypothesis did not receive a lot of attention in the profession until Barro (2006), who shows that income disasters have been frequent and large enough to justify Rietz's hypothesis and its accountability of the high equity premium. Subsequent papers such as Gabaix (2012), Gourio (2012), and Wachter (2013) find that incorporating time-varying probability and severity of disasters into the disaster hypothesis can help resolve a number of important puzzles in both macroeconomics and finance. Barro (2009) extends the cost-of-business-cycle literature starting from Lucas (1987) to rare disasters as documented in Barro (2006), and finds that their welfare cost is near a 20 percent drop in GDP every year. Instead of using the historical data on drops in GDP, Pindyck and Wang (2013) infer the statistical properties of the income disaster risk from economic and financial variables, and find that society is willing to pay a consumption tax of over 50 percent to eliminate this jump risk. Glover et al. (2014) examine the distributional consequences of the Great Recession, and find that a big negative technological shock hurts the old more than the young as a result of larger declines in equity prices relative to wages.

This paper is also related to the literature studying the implications of housing for the 
macroeconomy. Examples include Chambers, Garriga and Schlagenhauf (2009), Yang (2009), Fernandez-Villaverde and Krueger (2011), Sommer, Sullivan and Verbrugge (2013), Favilukis, Ludvigson and Van Nieuwerburgh (2013), and Iacoviello and Pavan (2013). These authors use OLG general equilibrium models to study various aspects of housing market dynamics. For example, Chambers, Garriga and Schlagenhauf (2009) build a model that takes into account mortgage structures and household-supplied rental properties, and show that the considerable mortgage innovation between 1994 and 2005 is the major driver of the observed boom in home ownership during the period. Sommer, Sullivan and Verbrugge (2013) investigate the effects of rising incomes, lower interest rates, and relaxing down payment requirements on house prices, and find that these factors can account for over half of the run-up in the house price-rent ratio in the last U.S. housing boom. My paper contributes to this literature by investigating the macroeconomic and welfare implications of the housing disaster risk. From this perspective, the current paper is closer to Favilukis, Ludvigson and Van Nieuwerburgh (2013) and Iacoviello and Pavan (2013), both of which study the impact of aggregate uncertainty on housing markets. The former paper finds that fluctuations in the U.S. price-rent ratio since the late 1990s are driven by changing risk premia in response to aggregate shocks and financial market liberalization, whereas the latter studies the life-cycle and business-cycle properties of housing and debt. In contrast to these two papers focusing on business-cycle-type technological shocks, my paper examines the effects of relatively rare disaster-type market-specific shocks on the macroeconomy.

The remainder of this paper is organized as follows. Section 2 describes the model and defines the equilibrium. Section 3 estimates the likelihood and magnitude of housing market disasters from the OECD and calibrates the benchmark model to the Canadian data. Section 4 investigates the welfare impact of the housing disaster risk as well as its macroeconomic implications. Section 5 concludes. Computational details on solving the model are contained in the appendix.

\section{The Model}

This section constructs a stochastic OLG general equilibrium economy, populated by overlapping generations of households, a representative firm and a government. Households supply their time and capital to the firm for its production of a numeraire non-housing good used for both consumption and investment. They also trade a bond in a financial market and a durable housing asset in a housing market. The economy is subject to rare housing disaster shocks. 


\subsection{Demographics}

The economy is populated by overlapping generations of households who are ex-ante heterogeneous. Let $j \in J=\left\{1, \ldots, j^{*}, \ldots, \bar{j}\right\}$ denote the age of a household, where the first period is when the household starts earning labor income, $j^{*}$ denotes a mandatory retirement age, and $\bar{j}$ stands for the maximum number of periods a household can live. In each period, a household faces an exogenous mortality risk. The survival probability to age $j+1$, conditional on being alive at age $j$, is denoted by $\psi_{j} \in[0,1]$, with $\psi_{0}=1$ and $\psi_{\bar{j}}=0$. This probability is assumed to be identical across households of the same age. There does not exist an annuity market for the mortality risk, so households cannot insure themselves against the risk. The model assumes that the total amount of wealth left by households who die in a given period is collected by the government and used for public consumption.

The population grows at rate $n$ and the associated age distribution $\left(\mu_{1}, \ldots, \mu_{\bar{j}}\right)$ is assumed to be fixed over time such that $\sum_{j=1}^{\bar{j}} \mu_{j}=1$ with

$$
\mu_{j+1}=\frac{\mu_{j} \psi_{j}}{1+n}, j=1, \ldots, \bar{j}-1,
$$

where $\mu_{j}>0$ denotes the share of the age- $j$ group in the total population.

\section{$2.2 \quad$ Preferences}

Households have Epstein-Zin preferences over consumption good $(c)$ and housing service $(h)$ as

$$
U_{j, t}=\left[\left(1-\beta \psi_{j}\right)\left(c_{j, t}^{\nu} h_{j, t}^{1-\nu}\right)^{1-\theta}+\beta \psi_{j} E_{j, t}\left(U_{j+1, t+1}^{1-\gamma}\right)^{\frac{1-\theta}{1-\gamma}}\right]^{\frac{1}{1-\theta}}, j \in J, t \in \mathbb{Z}_{+},
$$

where $\beta$ is the discount factor, $\nu$ is the Cobb-Douglas aggregator between the numeraire consumption good and the housing service, $\theta$ is the inverse of the intertemporal elasticity of substitution (IES), and $\gamma$ is the coefficient of relative risk aversion. ${ }^{5}$ Constant relative risk-aversion (CRRA) utility is a special case when $\theta=\gamma \cdot{ }^{6}$ The expectation operator $E_{j, t}$ is conditional on the information available at time $t$ for a household at age $j$, and expectations are formed with respect to the stochastic processes governing mortality and other shocks to be described later. It is assumed that there exists a linear technology that transforms one unit of housing stock

\footnotetext{
${ }^{5}$ The Cobb-Douglas aggregation between non-housing good and housing service is widely used in the housing literature. Fernandez-Villaverde and Krueger (2011) argue that Cobb-Douglas aggregation functions, which imply a unit elasticity between housing and non-housing goods, are an empirically reasonable choice.

${ }^{6}$ As pointed out in previous studies, such as Bansal and Yaron (2004), Barro (2009), and Gourio (2012), Epstein-Zin preferences, which separate risk aversion and IES, allow standard asset pricing models to overcome the notable defect associated with CRRA preferences that an increase in aggregate uncertainty raises stock prices.
} 
at the beginning of each period into one unit of housing service in that period. I also assume that households do not leave voluntary bequests upon their death, with the associated period utility normalized to zero for simplicity.

\subsection{Endowment}

Each period, households are endowed with one unit of time which is fully supplied to the firm for production, since they do not value leisure in the model. Households differ in their labor productivity over the life cycle, as reflected in a typical hump-shaped earning profile. Denote $\left\{\eta_{j}\right\}_{j=1}^{\bar{j}}$ as the age profile of productivity. Households at age $j$ receive labor earning $w_{t} \eta_{j}$, where $w_{t}$ is the market-determined wage at time $t$. I set $\eta_{j}=0$ for $j \geq j^{*}$, i.e., retirees are assumed to lose their productivity and no longer receive labor earnings. There is a pay-as-you-go social security program in the model, where workers pay payroll taxes from their labor earnings at rate $\tau$ and retirees receive the same amount of social security payment $b_{t}$ irrespective of their age. The retirement benefit equals a fraction $\rho$ of average labor earnings to be discussed later. The program is self-financing and managed by the government in the economy.

In sum, the net earning of an age- $j$ household at time $t$ is equal to

$$
e_{j, t}=(1-\tau) w_{t} \eta_{j}+b_{t} \mathbf{1}_{j \geq j^{*}}
$$

where $\mathbf{1}_{A}$ is an indicator function that takes value one when event $A$ occurs and zero otherwise.

\subsection{Production}

The numeraire good is produced by a competitive firm with a constant-returns-to-scale production technology:

$$
y_{t}=k_{t}^{\alpha} l_{t}^{1-\alpha}
$$

where $k_{t}$ and $l_{t}$ are total capital and labor input at time $t$, and $\alpha$ is the capital income share. The firm rents capital at interest rate $r_{t}$ and employs labor at wage $w_{t}$. Capital stock depreciates at rate $\delta_{k}$. Profit maximization implies that factors are paid their marginal product:

$$
r_{t}=\alpha\left(\frac{k_{t}}{l_{t}}\right)^{\alpha-1}-\delta_{k}, w_{t}=(1-\alpha)\left(\frac{k_{t}}{l_{t}}\right)^{\alpha}
$$

\subsection{Market Arrangements}

The economy consists of two asset markets, namely, a financial market and a housing market. In the financial market, households and firms trade a one-period bond which pays an interest rate $r_{t}$. Through the market, some households lend money to other households and the firm. 
Households also face a borrowing limit determined by the value of their houses. More precisely, denote $a_{t+1}$ and $h_{t+1}$ as a household's holdings of financial and housing assets for time $t+1$, respectively, and $p_{t}$ as prevailing house prices at time $t$ denominated in units of the numeraire consumption good. The household is subject to the following borrowing constraint:

$$
a_{t+1} \geq-(1-\lambda) p_{t} h_{t+1}, \lambda \in[0,1] .
$$

Inequality (6) says that each period the household can borrow up to a fraction $(1-\lambda)$ of the value of its house in that period, where parameter $\lambda$ can be interpreted as the down payment ratio. A positive $a$ means that the household is a saver or a bond buyer and vice versa.

In the housing market, aggregate housing supply is fixed at $\bar{h} .^{7}$ Houses are costly to maintain, since the consumption of housing services depreciates the housing stock. The periodic maintenance cost for a house of size $h$ is $\delta_{h} p_{t} h$, where $\delta_{h}$ represents the proportional maintenance expense.

The housing market is exposed to possible disastrous market crashes in the form of large drops in house prices. I assume that disaster shocks are identically and independently distributed, and arrive according to the following process:

$$
d_{h, t}=\left\{\begin{array}{ll}
\tilde{d}_{h} & \text { with probability } \pi_{h} \\
0 & \text { with probability } 1-\pi_{h}
\end{array} .\right.
$$

Each period, a disaster occurs with probability $\pi_{h}$, and is modeled as a proportional housing depreciation shock $\tilde{d}_{h}$. The distribution $F_{h}$ of the random variable $\tilde{d}_{h}$ is supported on $\left[\underline{d}_{h}, \bar{d}_{h}\right] \subset$ $\mathbb{R}_{++}$, and is calibrated to match the empirical distribution of house price declines in historical housing market disasters. Denote the range of the random variable $d_{h, t} a^{8}$

$$
D_{h}=\{0\} \times\left[\underline{d}_{h}, \bar{d}_{h}\right]
$$

Three remarks about the specification (7) are in order. First, this paper does not model the causes of housing market disasters, but instead assumes that they follow some exogenous yet empirically estimated distribution, because the focus of the current paper is on quantifying the welfare impact of the housing disaster risk. Second, the housing depreciation shock is a parsimonious way to model a housing market disaster characterized by large drops in house

\footnotetext{
${ }^{7}$ This assumption is made for a simplification purpose and is also frequently used in the literature such as Sommer, Sullivan and Verbrugge (2013) and Chu (2014). It is important to note that the total housing stock is only fixed relative to the population, whose size is assumed to be of measure one throughout the analysis.

${ }^{8}$ For simplicity, housing disasters are assumed to last for only one period. Barro (2006) finds that although economic crises typically last for a number of years in the data, allowing disasters to persist for more than one period does not greatly change the major prediction of the model. Meanwhile, the specification of five years as one model period in the calibration alleviates the possible bias caused by this assumption.
} 
prices. ${ }^{9}$ A similar depreciation shock is used in Iacoviello and Pavan (2013) to study mortgage default over the business cycle. ${ }^{10}$ Although the specification of housing depreciation shocks is more realistic for wars or natural disasters, it can also be interpreted as shocks to the quality of existing houses by affecting the effective units of housing assets brought from the previous period. In the model, housing depreciation shocks essentially play the role of negative housing wealth shocks, with this feature broadly consistent with housing market disasters in practice. Third, specification (7) does not consider continuous depreciation shocks in normal periods and thus ignores small fluctuations in house prices. This assumption is primarily made for model solvability, because taking into account those additional aggregate shocks would significantly increase the computational burden for solving the current heterogeneous-agent model. However, it is reasonable to believe that the basic insights about the welfare implications of housing disasters obtained in this paper will remain largely unaffected in more general settings.

\subsection{The Households' Problem}

All households are assumed to start their life with zero amount of financial assets and housing assets. At the beginning of each period $t$, a household observes the following five state variables: financial asset $a_{j, t}$, housing asset $h_{j, t}$, age $j$, realized disaster shock $d_{h, t}$, and the distribution function $\Phi_{t}$ of households across $\left(a_{j, t}, h_{j, t}, j\right) \in A \times H \times J$, where $A \subset \mathbb{R}$ and $H \subset \mathbb{R}_{+}$. Here, $\left(\Phi_{t}, d_{h, t}\right)$ characterizes the state of the economy at time $t$. Since the disaster shock $d_{h, t}$ is the only economic-wide shock in the model, the holdings of both financial and housing assets must be the same within each age group over time, provided that all households start their life with the same levels of financial assets and housing assets. As a result, the distribution $\Phi_{t}$ can be expressed as a discrete measure:

$$
\Phi_{t}=\sum_{j=1}^{\bar{j}} \mu_{j} \delta_{\left(a_{j, t}, h_{j, t}, j\right)} .
$$

After observing the state $\left(a_{j, t}, h_{j, t}, j, \Phi_{t}, d_{h, t}\right)$, the household chooses its non-housing consumption $c_{j, t}$ and new holdings of financial assets $a_{j, t+1}$ and housing assets $h_{j, t+1}$ to maximize

\footnotetext{
${ }^{9}$ Alternatively, one could use housing preference shocks to generate house price movements such as Iacoviello (2005), Iacoviello and Neri (2010), and Liu, Wang and Zha (2013).

${ }^{10}$ Housing depreciation shocks are similar in spirit to capital depreciation shocks proposed as important drivers of business cycles by papers such as Barro (2006, 2009), Gertler and Karadi (2011), and Gourio (2012).
} 
its lifetime utility formulated in the following Bellman equation:

$$
v\left(a_{j, t}, h_{j, t}, j, \Phi_{t}, d_{h, t}\right)=\max _{c_{j, t}, h_{j, t}^{\prime}, a_{j, t}^{\prime}}\left\{\begin{array}{c}
\left(1-\beta \psi_{j}\right)\left(c_{j, t}^{\nu} h_{j, t}^{1-\nu}\right)^{1-\theta} \\
+\beta \psi_{j} E_{j, t}\left[v\left(a_{j, t}^{\prime}, h_{j, t}^{\prime}, j+1, \Phi_{t+1}, d_{h, t+1}\right)^{1-\gamma}\right]^{\frac{1-\theta}{1-\gamma}}
\end{array}\right\}
$$

subject to the following constraints

$$
\begin{gathered}
c_{j, t}+a_{j, t}^{\prime}+p_{t} h_{j, t+1} \leq e_{j, t}+(1+r) a_{j, t}+\left(1-\delta_{h}-d_{h, t}\right) p_{t} h_{j, t}, \\
a_{j, t}^{\prime} \geq-(1-\lambda) p_{t} h_{j, t}^{\prime}, \quad c_{t} \geq 0, h_{j, t}^{\prime} \geq 0 .
\end{gathered}
$$

On the right-hand side of the budget equation (11), the first term $e_{j, t}$ is defined in (3) and it denotes the household's total earnings. The next two terms represent, respectively, the household's gross savings from the last period and the housing wealth after both physical and disasterinduced depreciation. Let $c(\cdot), a^{\prime}(\cdot)$ and $h^{\prime}(\cdot)$ be the optimal policy functions of the nonhousing consumption, financial position and housing position, respectively, and for simplicity denote $c_{j, t}=c\left(a_{j, t}, h_{j, t}, j, \Phi_{t}, d_{h, t}\right), a_{j, t}^{\prime}=a^{\prime}\left(a_{j, t}, h_{j, t}, j, \Phi_{t}, d_{h, t}\right)$ and $h_{j, t}^{\prime}=h^{\prime}\left(a_{j, t}, h_{j, t}, j, \Phi_{t}, d_{h, t}\right)$.

\subsection{Equilibrium}

I next define the recursive competitive equilibrium of this economy.

Definition 1 Given a replacement rate $\rho$ and an initial distribution $\Phi_{0}$, a recursive competitive equilibrium consists of prices $\left\{r_{t}, w_{t}, p_{t}\right\}$; aggregate variables $\left\{k_{t}, l_{t}\right\}$; a value function $v\left(a_{j, t}, h_{j, t}, j, \Phi_{t}, d_{h, t}\right)$, optimal policy functions $c\left(a_{j, t}, h_{j, t}, j, \Phi_{t}, d_{h, t}\right), a^{\prime}\left(a_{j, t}, h_{j, t}, j, \Phi_{t}, d_{h, t}\right)$ and $h^{\prime}\left(a_{j, t}, h_{j, t}, j, \Phi_{t}, d_{h, t}\right)$; public policies $\left\{\tau_{t}, b_{t}, g_{t}\right\}$; and a transition function $Q$ for $\Phi$ with $\Phi_{t+1}=Q\left(\Phi_{t}, d_{h, t}\right)$ such that

1. Given prices $r_{t}, w_{t}$ and $p_{t}$, the value function $v$ and policy functions $c, a^{\prime}$ and $h^{\prime}$ solve the household's utility maximization problem (10).

2. Given prices $r_{t}$ and $w_{t}$, aggregates $k_{t}$ and $l_{t}$ solve the firm's profit maximization problem by satisfying (5).

3. The social security program is self-financing:

$$
b_{t} \sum_{j=j^{*}}^{\bar{j}} \mu_{j}=\tau_{t} \sum_{j=1}^{j^{*}-1} \mu_{j} w_{t} \eta_{j} .
$$


4. Government expenditures equal accidental bequests:

$$
g_{t}=\sum_{j=2}^{\bar{j}} \mu_{j-1}\left(1-\psi_{j-1}\right)\left((1+r) a_{j, t}+\left(1-\delta_{h}-d_{h, t}\right) p_{t} h_{j, t}\right) .
$$

5. Markets clear:

(a) Financial market clears:

$$
\sum_{j=1}^{\bar{j}} \mu_{j} a_{j, t}^{\prime}=k_{t+1}
$$

(b) Housing market clears:

$$
\sum_{j=1}^{\bar{j}} \mu_{j} h_{j, t}^{\prime}=\bar{h}
$$

(c) Labor market clears:

$$
\sum_{j=1}^{\bar{j}} \mu_{j} \eta_{j}=l_{t}
$$

(d) Goods market clears:

$$
c_{t}+i_{t}+g_{t}+x_{t}=y_{t},
$$

where $c_{t}=\sum_{j=1}^{\bar{j}} \mu_{j} c_{j, t}, i_{t}=k_{t+1}-\left(1-\delta_{k}\right) k_{t}$ and $x_{t}=\left(\delta_{h}+d_{h, t}\right) p_{t} \bar{h}$.

6. The transition function $Q$ is consistent with individual behavior, i.e.,

$$
\Phi_{t+1}=Q\left(\Phi_{t}, d_{h, t}\right)=\sum_{j=1}^{\bar{j}} \mu_{j} \delta_{\left(a_{j-1, t}^{\prime}, h_{j-1, t}^{\prime}, j-1\right)},
$$

where $a_{j-1, t}^{\prime}=a^{\prime}\left(a_{j-1, t}, h_{j-1, t}, j-1, \Phi_{t}, d_{h, t}\right)$ if $j \geq 2$ and 0 if $j=1$, and $h_{j-1, t}^{\prime}$ is defined similarly.

The above definition is standard. For the social security program, the retirement benefit $b_{t}$ is assumed to equal a fraction $\rho$ of average labor earnings, i.e.,

$$
b_{t}=\rho \frac{\sum_{j=1}^{j^{*}-1} \mu_{j} w_{t} \eta_{j}}{\sum_{j=1}^{j^{*}-1} \mu_{j}}
$$

which is proportional to the wage rate $w_{t}$. Equations (19) and (12) then imply the following time-invariant payroll tax rate:

$$
\tau=\rho \frac{\sum_{j=j^{*}}^{\bar{j}} \mu_{j}}{\sum_{j=1}^{j^{*}-1} \mu_{j}}
$$


As expected, the payroll tax rate increases with the replacement ratio and the population size of retirees relative to workers.

The right-hand side of the government budget equation (13) represents the total wealth left by households who were alive yesterday but die today: the sum associated with $a_{j, t}$ represents the total financial wealth of those households, and that associated with $p_{t} h_{j, t}$ represents their total housing wealth after depreciation.

For market clearing conditions, equation (14) says that the net supply of financial assets must equal the aggregate capital stock employed by the firm. Meanwhile, since households supply all their time endowment to the firm, equation (16) implies that the aggregate labor supply is constant over time and equals $l=\sum_{j=1}^{j^{*}-1} \mu_{j} \eta_{j}$, given $\eta_{j}=0$ for $j \geq j^{*}$. In the goods-market clearing equation (17), the four terms on the left-hand side represent, respectively, the aggregate non-housing consumption $\left(c_{t}\right)$, investment in capital stock $\left(i_{t}\right)$, government expenditure $\left(g_{t}\right)$, and housing depreciation expenses $\left(x_{t}\right)$.

\section{Calibration}

This section describes the calibration of the model, where I estimate the parameters characterizing the likelihood and magnitude of housing market disasters using the historical OECD house price data, and the rest to match Canadian data over the period 2000-2012.

\subsection{Demographics and Preferences}

One period in the model is equivalent to five years. Households enter the model at age 20 (model age 1$)$ and can live up to age $95(\bar{j}=16)$. Retirement is mandatory at age $65\left(j^{*}=10\right)$. The conditional survival probabilities $\left\{\psi_{j}\right\}_{j=1}^{\bar{j}}$ are estimated using the 2007-2009 female life table from Statistics Canada. The average annual population growth rate is 0.011 in Canada since 2000, corresponding to a five-year growth rate of 0.056 . The age distribution $\left\{\mu_{j}\right\}_{j=1}^{\bar{j}}$ is then computed using equation (1).

For parameters characterizing preferences, the coefficient of relative risk aversion $\gamma$ is set at 2 , a value that lies in the middle of the range commonly used in the literature. The IES is set at 2 , which implies that $\theta=0.5$. It is worth noting that although there is a large debate about the value of IES in the literature as empirical estimates find both high and low numbers, an IES smaller than one would have the counterfactual implication that higher uncertainty increases the prices of risky assets, as pointed out for instance in Barro (2009) and Gourio (2012). In the quantitative exercise, the aggregator function of non-housing goods and housing services takes the form $c^{\nu}(h+\varepsilon)^{1-\nu}$. Here, $\varepsilon$ is an arbitrarily small positive number, making the utility function finite when $h=0$, which can be interpreted to mean that one can survive 
without a house but not without food. The aggregation parameter $v$ is set at 0.9 in the baseline calibration, in line with the estimated share of non-housing consumption in total expenditure in the literature. I calibrate the time discount factor $\beta$ such that the implied steady-state equilibrium interest rate matches the mortgage interest rate in the data. The choice of this target is motivated by the fact that the discount factor directly affects households' willingness to borrow and lend, and thus the interest rate. The average annualized real five-year mortgage rate is about 3.2 percent in Canada during the period from 2000 to 2012, which implies that $\beta=0.9$.

\subsection{Endowment and Production}

The no-disaster average labor productivity profile $\left\{\eta_{j}: j \in J\right\}$ is used to capture the typical hump-shaped earning profile over the life cycle. The age dependency of labor productivity is modeled by the following regression equation:

$$
\log \eta_{j}=\beta_{1} * a g e_{j}+\beta_{2} * a g e_{j}^{2}+\varepsilon_{j}, j<j^{*}
$$

where $\varepsilon_{j}$ is the associated residual term. The values of $\beta_{1}$ and $\beta_{2}$ are taken from Meh, Ríos-Rull and Terajima (2010), who estimate age-class specific labor endowments using the panel wage data of the 1999-2004 Survey of Labour Income Dynamics from Statistics Canada. The survey contains information on Canadian households regarding their labor supply and income over time. The age-dependent productivity $\eta_{j}$ is approximated by the wage rate, which is defined by the total wage and salary income divided by the total hours worked. The estimated parameter values are $\beta_{1}=0.076$ and $\beta_{2}=-0.00085$.

The replacement rate $\rho$ is set at 0.4 , which implies a payroll tax rate $\tau$ of 0.13 by (20). I set the capital income share $\alpha=0.33$, and the capital depreciation rate $\delta_{k}=0.1$, in line with the average depreciation rate of the fixed non-residential capital stock in Canada since 2000.

\subsection{Housing Market and Disaster Risks}

For parameters that capture the housing market, I set the average down payment ratio $\lambda=0.15$ in the benchmark model. This corresponds to a loan-to-value ratio of 0.85 , in accordance with the average of the ratio in Canada in the past decade. The proportional home maintenance cost $\delta_{h}$ is set at 0.05 in the baseline. The aggregate housing stock $\bar{h}$ is estimated as follows. First, I obtain the value of the total fixed residential capital stock $h_{2007}$ and household disposable income $y_{2007}$ observed in 2007 from Statistics Canada. This gives an estimated ratio $h_{2007} / y_{2007}$ equal to 1.84 . Second, using this ratio, I calculate the housing stock $\bar{h}$ in the model as $\bar{h}=$

$\frac{h_{2007}}{5 \times y_{2007}} \times \bar{y}=1.41$, where $\bar{y}$ represents the household disposable income in the steady-state 
equilibrium, and the factor 5 in the denominator makes the stock-income ratio consistent with the five-year model period.

Table 1: Housing market disasters in the OECD

\begin{tabular}{lcccc}
\hline \multirow{2}{*}{ Country } & Sample period & \multicolumn{2}{c}{ Disaster period } & \% Decline in real house prices \\
\cline { 2 - 4 } Austria & & Peak & Trough & \\
Belgium & $1987-2012$ & 1992 & 2001 & 24.8 \\
Canada & $1973-2012$ & 1979 & 1985 & 37.5 \\
Denmark & $1981-2012$ & 1981 & 1985 & 24.4 \\
Finland & $1992-2012$ & 2007 & 2012 & 28.0 \\
France & $1988-2012$ & 1989 & 1993 & 43.9 \\
Germany & $1992-2012$ & 1992 & 1998 & 30.9 \\
Greece & $1990-2012$ & 1995 & 2009 & 26.2 \\
Japan & $1994-2012$ & 2007 & 2012 & 34.3 \\
& $1955-2012$ & 1973 & 1977 & 32.0 \\
Norway & & 1990 & 2005 & 67.5 \\
Spain & $1955-2012$ & 1987 & 1992 & 43.1 \\
Sweden & $1995-2012$ & 2007 & 2012 & 30.8 \\
Switzerland & $1986-2012$ & 1990 & 1993 & 26.7 \\
United Kingdom & $1970-2012$ & 1973 & 1977 & 26.1 \\
United States & $1969-2012$ & 1973 & 1977 & 39.0 \\
\hline
\end{tabular}

I next describe the estimation of the likelihood and magnitude of housing market disasters based on historical housing market experiences in twenty OECD countries. ${ }^{11}$ I first obtain the up-to-date nominal house price indices of the twenty countries from the property price statistics by the Bank for International Settlements, which in turn gathers the data from national sources. ${ }^{12}$ These price indices are then deflated using consumer price indices from the OECD. In this paper, a housing market disaster is defined as cumulative peak-to-trough declines in real house prices of 20 percent or more. As shown in Table 1, I identify 18 housing disasters in the 616 observation years for the twenty countries in the sample, where fifteen of the

\footnotetext{
${ }^{11}$ Countries include Australia, Austria, Belgium, Canada, Denmark, Finland, France, Germany, Greece, Italy, Japan, the Netherlands, New Zealand, Norway, Portugal, Spain, Sweden, Switzerland, the United Kingdom and the United States.

${ }^{12}$ Due to the limited availability of house price data in most countries, the sample periods of international house prices are typically shorter than their GDP counterparts, as in Barro (2006), and also vary across countries, with the starting periods ranging from as early as 1955 to the 1990s.
} 
twenty countries have experienced at least one housing disaster, with Japan, Switzerland and the United Kingdom having undergone two. ${ }^{13}$ This implies an unconditional probability of housing market disasters equal to 3 percent each year, corresponding to roughly one disaster per country every 34 years. A housing disaster is found to last about 6.4 years on average, and the magnitude of house price declines ranges between 24 and 68 percent, with an average of about 34 percent. As for the size distribution $F_{h}$ of the housing depreciation shock $\tilde{d}_{h}$ upon the occurrence of a disaster, I assume that it is generic. ${ }^{14}$ More precisely, I calibrate $\tilde{d}_{h}$ to be 4.8 such that the model-generated declines in house prices after a housing disaster hits the steady-state equilibrium equal the sample average of 34 percent.

\subsection{Computation}

I solve for the competitive equilibrium using the method developed by Krusell and Smith (1997, 1998), which has been widely used in the study of heterogeneous agent models with aggregate uncertainty. It is assumed that households are boundedly rational in the sense that they use only partial information to predict the law of motion for the state variables. More precisely, households use only a subset of the moments of the distribution $\Phi_{t}$ instead of the whole distribution to deduce prices. I postulate that the aggregate capital stock $k_{t}$ is a sufficient statistic to represent the distribution $\Phi_{t}$, and the laws of motions of $k_{t}$ and house prices $p_{t}$ take the following functional forms:

$$
\begin{aligned}
\ln k_{t+1} & =\alpha_{1}\left(d_{h, t}\right)+\alpha_{2}\left(d_{h, t}\right) \ln k_{t} \\
\ln p_{t} & =\alpha_{3}\left(d_{h, t}\right)+\alpha_{4}\left(d_{h, t}\right) \ln k_{t}
\end{aligned}
$$

where coefficients $\left\{\alpha_{i}\left(d_{h, t}\right)\right\}_{i=1}^{4}$ are forecasting parameters associated with the aggregate disaster shock $d_{h, t}$. Since $d_{h, t}$ takes only two values in the benchmark calibration, there are in total eight coefficients to be estimated. With the above specifications, the recursive competitive equilibrium defined in the last section can be approximated by an otherwise-identical equilibrium, except that households solve the following optimization problem with partial information:

$$
v\left(a_{j, t}, h_{j, t}, j, k_{t}, d_{h, t}\right)=\max _{c_{j, t}, h_{j, t}^{\prime}, a_{j, t}^{\prime}}\left\{\begin{array}{c}
\left(1-\beta \psi_{j}\right)\left(c_{j, t}^{\nu} h_{j, t}^{1-\nu}\right)^{1-\theta} \\
+\beta \psi_{j} E_{j, t}\left[v\left(a_{j, t}^{\prime}, h_{j, t}^{\prime}, j+1, k_{t+1}, d_{h, t+1}\right)^{1-\gamma}\right]^{\frac{1-\theta}{1-\gamma}}
\end{array}\right\}^{\frac{1}{1-\theta}},
$$

\footnotetext{
${ }^{13}$ The five countries having no housing disasters in their sample periods are Australia (1987-2012), Italy (1990-2011), the Netherlands (1995-2012), New Zealand (1980-2012) and Portugal (1988-2012).

${ }^{14}$ Barro and Jin (2011) and Pindyck and Wang (2013) explicitly model the size distributions of income disasters in a representative-agent framework. However, taking into account the size distribution of declines in house prices would greatly increase the computational cost for solving the current heterogeneous-agent model with aggregate uncertainty. Therefore, for model tractability, I assume a generic distribution in the calibration.
} 
subject to (22), (23) and other standard constraints imposed for problem (10). The resulting model-generated moments based on the approximate policy functions are simulated over a long period of time, and compared to those perceived by households. If they are close enough, then one obtains a good approximation of the equilibrium. Otherwise, one could try different functional forms for the forecasting functions (22) and (23), or include additional moments of the distribution $\Phi_{t}$. The details of the computation scheme are described in the appendix.
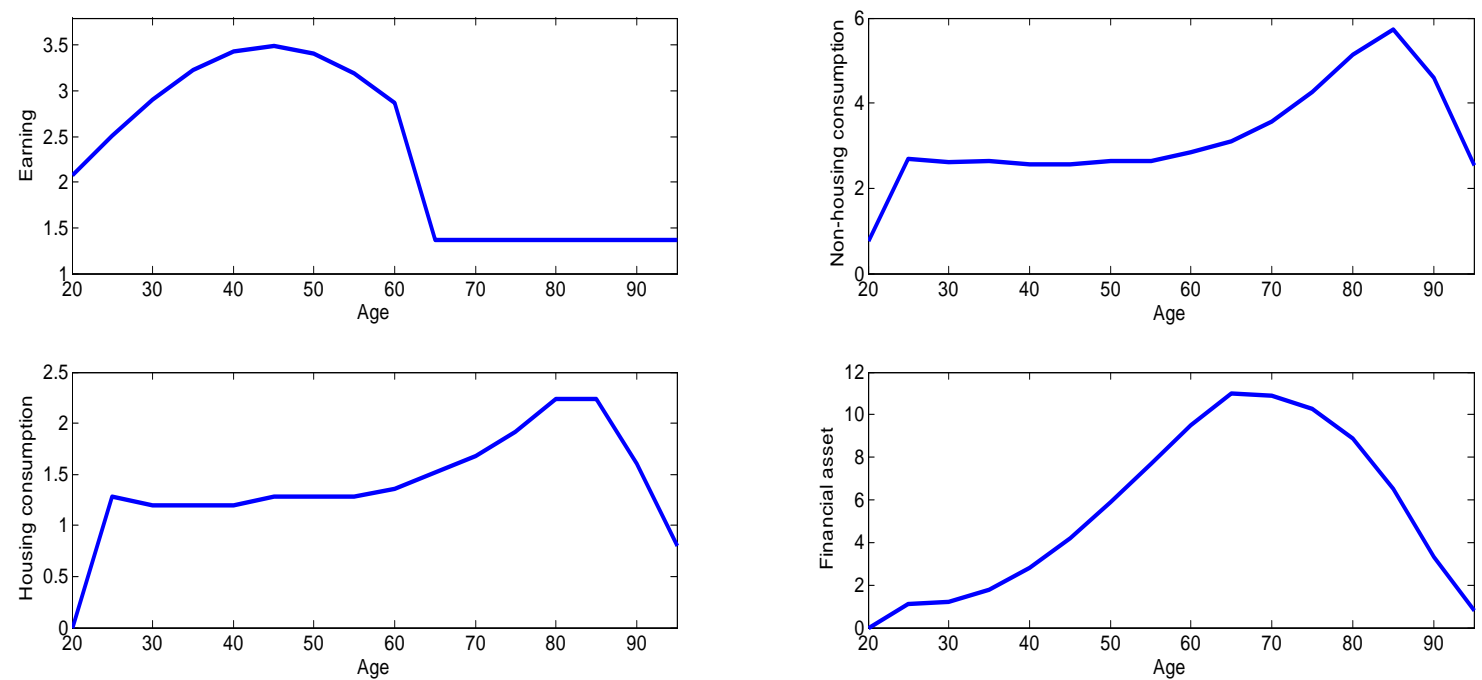

Figure 2: Simulated life-cycle profiles

Figure 2 shows the model-simulated life-cycle profiles of earnings adjusted for social security, non-housing consumption, housing consumption and financial assets in normal periods. The patterns of the profiles resemble those documented in previous studies on the lifecycle consumption-saving behavior such as Yang (2009) and Fernandez-Villaverde and Krueger (2011). The upper-left panel shows that labor earnings exhibit a hump shape over the life, peaking at around age 45 and remaining equal to social security benefits after retirement. The upper-right and lower-left panels of the figure plot, respectively, the age distributions of the consumption of non-housing goods and housing services, both of which display a hump-shaped pattern. ${ }^{15}$ For example, households buy houses in their 20 s to reap the benefits of housing service and collateral insurance. These two benefits of housing prevent households from downsizing their houses quickly until very late in life, when there comes a need to liquidate their housing wealth to finance non-housing consumption. This hump-shape pattern of housing consumption suggests that a steep decline in house prices would likely hurt the old more than the young. Finally, the lower-right panel of the figure shows a hump-shaped life-cycle profile of financial

\footnotetext{
${ }^{15}$ It is worth noting that the life-cycle profiles of housing and non-housing behave similarly, a result due to the Cobb-Douglas aggregation between housing and non-housing consumption in (2) as well as the absence of housing adjustment cost in the current model.
} 
wealth. Households typically hold few financial assets when they are young, because of the down payment requirement for their housing purchase. After the purchase, they start saving in financial assets to prepare for retirement, with their financial wealth peaking at age 65 . Once retired, households sell their financial assets to fund non-housing consumption.

\section{The Welfare Impact of Housing Disasters}

This section employs the calibrated model to quantify the welfare impact of the housing disaster risk on the Canadian economy. I first propose two welfare cost measures of housing disasters based on both specific age groups and the society as a whole. I then analyze the patterns of welfare implications derived from the benchmark model by examining the macroeconomic effects of this disaster risk in both disaster and normal periods. I conclude this section with a sensitivity analysis of the welfare cost estimation.

\subsection{Measuring the Welfare Cost}

To measure the welfare cost of the housing disaster risk, I compare the welfare of the benchmark economy to that of an otherwise-identical no-disaster economy $\left(\pi_{h}=0\right)$ based on a utilitarian welfare criterion. First, I measure the welfare impact of this disaster risk from the perspective of a specific age group. Define the ex-ante expected utility of a household at age $j \in J$ in the benchmark economy as

$$
V_{j}=E\left[v\left(a_{j, t}, h_{j, t}, j, \Phi_{t}, d_{h, t}\right)\right]
$$

where the value function $v$ is defined in (10), and the expectation is taken over all possible combinations of the financial asset $a_{j, t}$, the housing asset $h_{j, t}$, the distribution $\Phi_{t}$ of households and the housing disaster shock $d_{h, t}$ in equilibrium. Here, $V_{j}$ can be interpreted as the long-run welfare of an age- $j$ household. Note that the welfare criterion (25) is utilitarian, since it weighs lifetime utilities with their respective probabilities. ${ }^{16}$ Next denote

$$
\bar{V}_{j}=\bar{v}\left(\bar{a}_{j}, \bar{h}_{j}, j\right)
$$

as the lifetime utility of an age- $j$ household in the no-disaster economy, associated with the optimal choices of non-housing goods, housing services and holding of financial assets $\left\{\left(\bar{c}_{k}, \bar{h}_{k}, \bar{a}_{k}\right): k \geq j\right\}$ over remaining periods of life in the steady-state equilibrium, where $\bar{v}$ is the corresponding value function in the no-disaster economy. The welfare cost of the housing disaster risk from an age- $j$ household's perspective is then measured by a uniform percentage decrease $\xi_{j}$ in the consump-

\footnotetext{
${ }^{16}$ Harenberg and Ludwig (2014) use a similar welfare measure based on a newborn to evaluate different social security systems in an OLG model with recursive preferences and aggregate uncertainty.
} 
tion of non-housing goods that the household is willing to give up over remaining periods of life in the no-disaster economy in order to be as well off as living in the benchmark economy. By the homotheticity of Epstein-Zin preferences (2), one has that

$$
\xi_{j}=1-\frac{V_{j}}{\bar{V}_{j}}
$$

where $\xi_{j}>(<) 0$ implies that eliminating the housing disaster risk is welfare increasing (decreasing) from the point of view of an age- $j$ household.

The second measure of the welfare impact of housing disasters is considered from an aggregate perspective. I define the utilitarian social welfare in the benchmark economy as

$$
V=E\left[\sum_{j=1}^{\bar{j}} \mu_{j} v\left(a_{j, t}, h_{j, t}, j, \Phi_{t}, d_{h, t}\right)\right]=\sum_{j=1}^{\bar{j}} \mu_{j} V_{j}
$$

where $\mu_{j}$ is the share of age- $j$ households in the total population and $V_{j}$ is defined in (25). Here, $V$ represents the average welfare of all the living households. Accordingly, the social welfare in the no-disaster economy can be written as

$$
\bar{V}=\sum_{j=1}^{\bar{j}} \mu_{j} \bar{v}\left(\bar{a}_{j}, \bar{h}_{j}, j\right)=\sum_{j=1}^{\bar{j}} \mu_{j} \bar{V}_{j}
$$

with $\bar{V}_{j}$ given by (26). The aggregate welfare cost of the housing disaster risk is measured by an age-independent uniform percentage decrease $\xi$ in the consumption of non-housing goods by all households in the no-disaster economy, such that the society is as well off as in the benchmark economy. Similarly, the homotheticity of Epstein-Zin preferences implies that

$$
\xi=1-\frac{V}{\bar{V}}
$$

Removing the housing disaster risk leads to a welfare gain for the society if $\xi$ is positive, and a welfare loss if $\xi$ is negative.

The first row of Table 2 reports the welfare costs of the housing disaster risk based on the benchmark model. It shows that despite their rarity, the aggregate welfare cost of housing disasters is large, with $\xi=0.0524$, i.e., Canadian households are on average willing to give up 5.24 percent of their non-housing consumption each year in order to eliminate this disaster risk. Meanwhile, the welfare evaluation of this risk differs considerably in magnitude across age groups, with a welfare cost as high as 10 percent of annual non-housing consumption for the old, but near zero for the young. More noticeable is that households in their 20s find the presence of this risk welfare beneficial, which is equivalent to a uniform 1.19 percent increase in their non- 
housing consumption over the life cycle. This notable asymmetry in the evaluation of housing disasters across age groups suggests that households at different ages hold different attitudes toward the presence of this risk. To understand these patterns of the welfare implications of housing disasters, it is useful to fully investigate how the presence of this disaster risk impacts household life-cycle portfolio allocations, asset prices and quantities.

Table 2: Welfare analysis of rare housing disasters

\begin{tabular}{llllllllll}
\hline \hline & \multicolumn{10}{c}{ Age } & \multicolumn{1}{c}{ Ovelfare cost $(\%)$} \\
\cline { 2 - 10 } & Overall & $20-29$ & $30-39$ & $40-49$ & $50-59$ & $60-69$ & $70-79$ & $80-89$ & $90-99$ \\
\hline Benchmark & 5.24 & -1.19 & 1.01 & 3.89 & 6.24 & 8.02 & 9.87 & 11.2 & 10.1 \\
$\pi_{h}=0.02$ & 4.54 & -1.33 & 0.571 & 3.27 & 5.40 & 7.13 & 8.91 & 10.2 & 8.68 \\
$\pi_{h}=0.01$ & 3.10 & -1.69 & -0.407 & 1.94 & 3.75 & 5.44 & 7.01 & 7.84 & 5.21 \\
$\gamma=4$ & 4.98 & -1.51 & 0.667 & 3.56 & 5.95 & 7.88 & 9.90 & 11.1 & 8.78 \\
$\theta=0.8$ & 4.26 & -1.45 & 0.418 & 2.67 & 4.81 & 6.74 & 8.55 & 9.75 & 9.70 \\
$\nu=0.8$ & 8.56 & -3.62 & 0.370 & 5.30 & 9.67 & 13.8 & 17.6 & 19.4 & 15.2 \\
$\bar{h}=1.8$ & 5.22 & -1.18 & 1.14 & 3.88 & 6.09 & 8.08 & 9.79 & 10.9 & 10.7 \\
\hline
\end{tabular}

Notes: In the benchmark, $\pi_{h}=0.03, \gamma=2, \theta=0.5, v=0.9, \bar{h}=1.41$.

\subsection{Analyzing the Welfare Implications}

This subsection uses the benchmark model to examine the effects of the existence of the housing disaster risk on the macroeconomy in both disaster and normal episodes.

First, I study how macroeconomic aggregates and life-cycle profiles of asset holdings and consumption respond to a realized housing disaster. To do so, I assume in the simulation that the sequence of aggregate disaster states involves a long period of normal times, a disaster hitting the housing market in period 1 and a return to normal times in subsequent periods. Figure 3 displays the dynamics of macroeconomic aggregates after the disaster shock, which shows that a housing disaster leads to a long-lasting economic recession. During the disaster, house prices decline immediately, with the loss in housing wealth reducing the aggregate household savings and thus the capital supply. ${ }^{17}$ The resulting higher interest rate discourages investment and labor hiring, which consequently leads to declines in wages, output and consumption. ${ }^{18}$ After the disaster, the economy starts recovering, but it takes about fifty years to fully return to its pre-disaster state.

Table 3 reports the responses of consumption and saving to the housing disaster shock across age groups, by computing the percentage change in the holdings of financial assets and

\footnotetext{
${ }^{17}$ The house price decline generated by the benchmark model is smaller than the observed average price decline in the OECD sample, because housing disasters are unexpected for households in the baseline calibration.

${ }^{18}$ Note that the change in interest rate occurs one period later than the collapse in house prices because the capital stock in each period is predetermined in the model; so is the equilibrium interest rate, according to (5).
} 

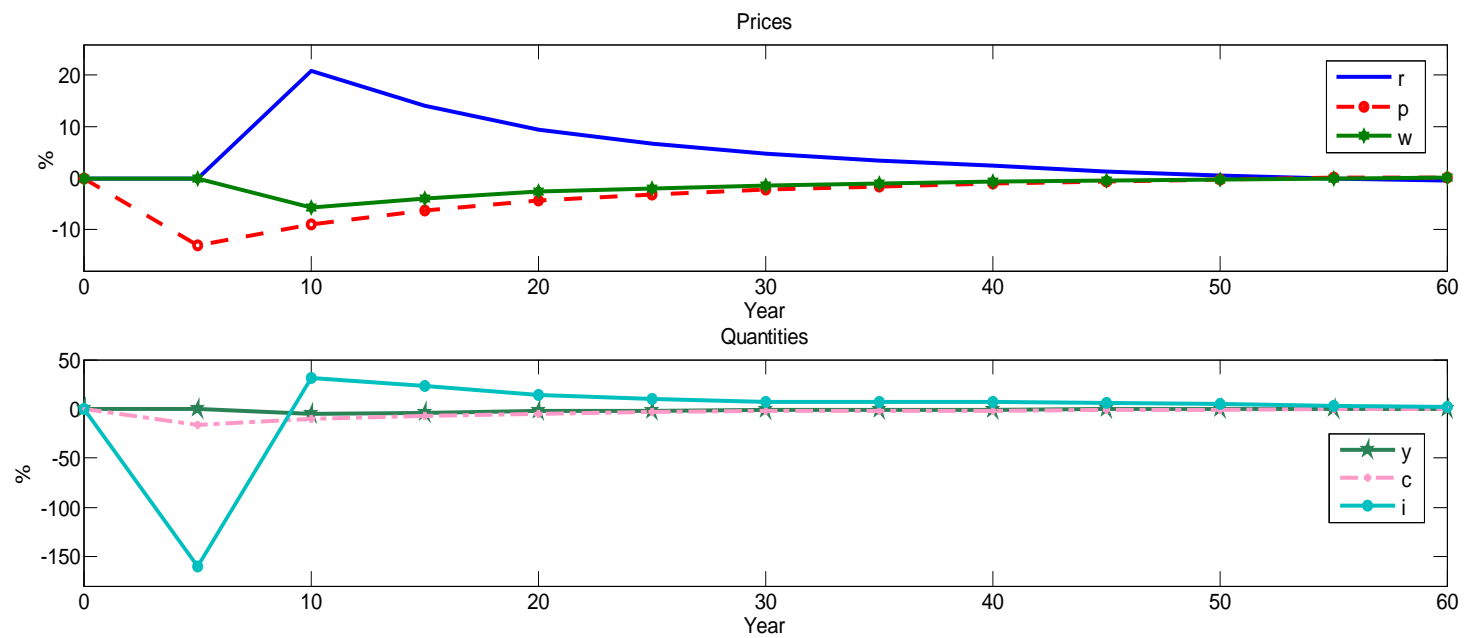

Figure 3: Responses of macroeconomic aggregates to a housing disaster

the consumption of non-housing goods and housing services for different age groups right after the disaster. As seen in the first row of the table, holdings of financial assets decrease for nearly all age groups due to the large negative housing wealth shock, with the most pronounced decline observed for households in their 30s and 90s. The only exception are households in their 20s, who instead slightly increase their financial assets, because of decreased expenditures on housing purchases thanks to depressed house prices. The second row of the table shows that young and middle-aged households either upsize or keep their current houses, whereas old households downsize their houses, suggesting that the age distribution of housing consumption would spread out after the disaster. The asymmetric responses in housing consumption across age groups are due to the hump-shaped profile of life-cycle housing consumption. As seen in Figure 2, old households typically hold more housing assets than their young and middle-aged counterparts, and they are also the main house sellers in the housing market as they become aged. A housing disaster forces them to decrease their holdings of housing assets in order to mitigate the negative wealth effect on their non-housing consumption. In contrast, young and middle-aged households hold relatively fewer housing assets and are thus less affected by drops in house prices. As a matter of fact, a large decline in house prices even induces young households in their 20s to upsize their houses in the disaster episode. The final row of Table 3 shows that non-housing consumption declines across all age groups, with the decline being most pronounced for older households because they are most exposed to the housing disaster. To sum up, due to the wealth effect, a realized housing disaster leads to a large recession. However, younger households fare better than older households, because declines in house prices favor the young, who purchase houses at lower cost, but hurt the old, who rely on house sales to finance non-housing consumption. 
Table 3: Life-cycle impact of a realized disaster $(\%)$

\begin{tabular}{lllllllll}
\hline \hline Age & $20-29$ & $30-39$ & $40-49$ & $50-59$ & $60-69$ & $70-79$ & $80-89$ & $90-99$ \\
\hline$\frac{\triangle a}{a}$ & 9.09 & -53.6 & -24.4 & -14.8 & -9.79 & -11.3 & -17.0 & -32.1 \\
$\frac{\Delta h}{h}$ & 6.25 & 0.00 & 0.00 & 3.02 & 2.90 & 2.39 & -5.09 & -11.8 \\
$\frac{\Delta c}{c}$ & -17.7 & -17.3 & -13.3 & -13.3 & -13.6 & -15.5 & -20.1 & -28.6 \\
\hline
\end{tabular}

Next, I study how the likelihood of having a disaster affects the macroeconomy in normal periods. In Table 4, I calculate the percentage differences in macroeconomic aggregates relative to their counterparts in the no-disaster economy. ${ }^{19}$ The table shows that the presence of the disaster risk has a sizable impact on macroeconomic aggregates in normal periods, with lower house prices and interest rate but higher wages, output, consumption and investment. This result is due to households' portfolio reallocation from housing to financial assets. When riskaverse households know there is a non-trivial likelihood of experiencing a housing disaster in the future, their demand for housing assets falls, which drives down house prices. Due to the substitution effect, households become more willing to save in financial assets, which lowers the interest rate. Declining borrowing costs encourage investment and labor hiring, leading to higher wages, output and consumption.

\begin{tabular}{cccccc}
\multicolumn{6}{c}{ Table 4: Changes in aggregates (\%) } \\
\hline \hline$\frac{\Delta p}{p}$ & $\frac{\Delta r}{r}$ & $\frac{\Delta w}{w}$ & $\frac{\Delta y}{y}$ & $\frac{\Delta c}{c}$ & $\frac{\Delta i}{i}$ \\
\hline-75.2 & -14.6 & 4.92 & 4.92 & 7.57 & 15.7 \\
\hline
\end{tabular}

Table 5 reports the effects of the disaster risk on the life-cycle consumption and saving in normal periods. As seen in the first row, the likelihood of having a disaster in the future induces more holdings of financial assets across all age groups due to the substitution effect between financial and housing assets. The increase is especially pronounced for households in their 20s and 90s. The very young households own more financial wealth by benefiting from decreased house prices as well as increased wages, as seen in Table 4. In contrast, the very old households, who rely heavily on liquidating their housing wealth to finance non-housing consumption, become more willing to rebalance their wealth toward financial assets given the downside risk in house prices. The second row of Table 5 shows that, anticipating a likely downturn in the housing market, older households would sell more of their housing assets, which drives down house prices. This, in turn, makes houses more affordable to home buyers, especially those at the early stage of the life cycle. The last row of the table shows that the presence of the disaster risk increases non-housing consumption of all age groups except those in their 80s. The increase is most significant for young households in their 20s and 30s,

\footnotetext{
${ }^{19}$ The equilibrium aggregates in normal periods are solved by simulating the economy using the forecasting functions (22) and (23) associated with normal times until both macroeconomic aggregates and cross-household distributions become stable.
} 
thanks to lower house prices and higher wages. To sum up, due to the substitution effect, the presence of the housing disaster risk induces a resource reallocation from the housing sector to the production sector in normal periods. The resulting lower house prices, however, benefit younger households more than the old.

In light of the above analysis of the macroeconomic impact of the housing disaster risk, one can readily explain the welfare implications found in the last subsection. From the society's perspective, although the presence of this disaster risk would result in a welfare beneficial resource reallocation from the housing sector to the production sector in normal periods, the associated welfare gain is dominated by the welfare loss in the large recession triggered by a housing disaster due to diminishing marginal utility of consumption. Overall, the society would willingly devote a significant amount of resources to eliminating the housing disaster risk. Meanwhile, the above analysis shows that, compared to the old, younger households suffer less in disaster periods, due to their smaller holdings of housing assets, and they also benefit more in normal periods from purchasing houses at lower cost, due to the incorporation of disaster risk in households' portfolio allocation decisions. This justifies the marked asymmetry in the welfare cost evaluation of the housing disaster risk across age groups.

Table 5: Life-cycle impact of a rise in disaster probability (\%)

\begin{tabular}{lllllllll}
\hline \hline Age & $20-29$ & $30-39$ & $40-49$ & $50-59$ & $60-69$ & $70-79$ & $80-89$ & $90-99$ \\
\hline$\frac{\triangle a}{a}$ & 267 & 77.5 & 16.8 & 7.97 & 5.15 & 6.98 & 21.8 & 120 \\
$\frac{\triangle h}{h}$ & 14.3 & 7.14 & 6.90 & 3.34 & 5.90 & -6.14 & -15.9 & -26.4 \\
$\frac{\triangle c}{c}$ & 17.3 & 16.2 & 10.4 & 6.28 & 4.85 & 0.851 & -1.67 & 5.32 \\
\hline
\end{tabular}

\subsection{Sensitivity Analysis}

This subsection conducts a sensitivity analysis of the welfare cost estimation of the housing disaster risk, with results reported in Table 2. In this analysis, except for those parameters explicitly under investigation, the rest are all maintained at their benchmark parameterization. Apparently, the analysis shows that calculating welfare costs using those alternative parameters does not significantly change either the magnitude or life-cycle patterns observed in the benchmark calculation. The individual effects of those parameters are presented as follows.

The first parameter of interest is the housing disaster probability $\pi_{h}$. Examining the impact of the parameter is especially useful because the baseline value of 3 percent as estimated from the OECD sample might be subject to some caveats. For example, the probability estimate could be biased due to a small sample problem, since house price series are not sufficiently long in many of the sample OECD countries. Also, the estimate is based on the assumption of parameter stability across countries, and it might thus under- or overstate country-specific 
risks depending on a country's regulatory and institutional features. ${ }^{20}$ For this consideration, I re-estimate the welfare costs for two different probabilities, with results reported in the second and third rows of Table 2. Not surprisingly, a decrease in the disaster probability lowers the welfare benefits of eliminating the disaster risk from the perspective of either an individual age group or the society as a whole. For example, when the likelihood of having a housing disaster declines from 3 to 2 percent every year, the aggregate welfare cost of the housing disaster risk decreases from 5.24 to 4.54 percent of annual non-housing consumption.

The fourth row of Table 2 shows that increasing the coefficient of relative risk aversion $\gamma$ surprisingly makes the housing disaster risk less welfare costly. This is due to the fact that when households are more risk averse, they tend to allocate more of their wealth from housing to financial assets, leading to lower house prices and larger output and consumption in normal periods. This consequently makes housing disasters less costly for a given disaster probability. The fifth row of the table finds that an increase in $\theta$, or equivalently a decrease in IES $1 / \theta$, reduces the welfare benefits of eliminating the housing disaster risk. This is because a decrease in IES implies that households are more averse to intertemporal fluctuations in consumption and thus tend to hold more financial assets but fewer housing assets. Similar to an increase in the disaster probability, this resource allocation alleviates the negative welfare impact of housing disasters. The sixth row of the table shows that decreasing the Cobb-Douglas aggregator $\nu$ of consumption goods relative to housing services raises the welfare benefits of removing the housing disaster risk. When households value housing services more than before, they tend to hold more housing assets and are thus more exposed to housing disaster shocks, explaining why this disaster risk becomes more welfare costly. The last row of the table shows that an increase in housing stock $\bar{h}$ has limited effects on the welfare costs of the housing disaster risk, because, all else equal, increased house supply lowers house prices but leaves households' housing wealth mostly unaffected.

In conclusion, as far as the Canadian economy is concerned, despite the rarity of housing disasters, households would be willing to give up around 5 percent of their non-housing consumption each year to eliminate this disaster risk. However, the welfare evaluation varies considerably across households, with the old benefiting more from the elimination of the risk.

\footnotetext{
${ }^{20}$ For example, Canada has relatively more conservative mortgage market arrangements than the United States in several dimensions. First, the share of subprime market has remained much lower in Canada than in the United States before the crisis. Also, private-label securitization, which typically has weaker underwriting standards than agency securitizations, is almost non-existent in Canada, but experienced large growth in the United States in the run-up to the housing market collapse. Furthermore, government guarantee on mortgagebacked securities is explicit in Canada but implicit in the United States, with mortgage default insurance for the lender being supplied by the private sector in the United States but by the public sector in Canada.
} 


\section{Conclusion}

This paper examines the welfare cost of rare housing disasters in an overlapping generations general equilibrium model. I calibrate the likelihood and magnitude of housing disasters from historic housing market experiences in the OECD, and find that housing market disasters occur with a probability of 3 percent every year. The model shows that despite their rarity, the aggregate welfare cost of housing disasters is large, since Canadian households would give up around 5 percent of their non-housing consumption each year to eliminate this disaster risk. However, the welfare evaluation of this risk differs considerably in magnitude across age groups, with a welfare cost as high as 10 percent of annual non-housing consumption for the old, but near zero for the young. This notable asymmetry stems from the fact that, compared to the old, younger households suffer less from house price declines in disaster periods, due to smaller holdings of housing assets, and they benefit more from purchasing houses at lower cost in normal periods, due to the negative effect of disaster risk on house prices.

A valuable extension of this paper would be to explicitly model the causes of housing market disasters, which would improve our understanding of how to reduce the probability or impact of those events. Also interesting would be an examination of the effects of time-varying housing disaster risk on the dynamics of house prices and other macroeconomic aggregates, since changes in disaster risk alone could have meaningful macroeconomic consequences. ${ }^{21}$ Furthermore, it would be useful to consider the possible interdependence between different types of economic disasters, such as housing disasters versus income disasters, as considered in Barro (2006), and compare their macroeconomic and welfare implications.

\section{References}

[1] Bansal, R. and A. Yaron (2004), "Risks for the Long Run: A Potential Resolution of Asset Pricing Puzzles," Journal of Finance, 59(4), 1481-1509.

[2] Barro, R. (2006), "Rare Disasters and Asset Markets in the Twentieth Century," Quarterly Journal of Economics, 121(3), 823-866.

[3] Barro, R. (2009), "Rare Disasters, Asset Prices, and Welfare Costs," American Economic Review, 99(1), 243-264.

[4] Barro, R. and T. Jin (2011), "On the Size Distribution of Macroeconomic Disasters," Econometrica, 79(5), 1567-1589.

\footnotetext{
${ }^{21}$ Although not specifically suited for addressing the question of the impact of time-varying disaster risk, this paper shows that a small permanent change in disaster probability could generate large fluctuations in both prices and quantities, as seen in Table 4.
} 
[5] Barro, R. and J. Ursúa (2008), "Macroeconomic Crises since 1870," Brookings Papers on Economic Activity, (1), 255-335.

[6] Bauer, G. (2014), "International House Price Cycles, Monetary Policy and Risk Premiums," Bank of Canada Working Paper, No. 2014-54.

[7] Chambers, M., C. Garriga and D. Schlagenhauf (2009), "Accounting for Changes in the Homeownership Rate," International Economic Review, 50(3), 677-726.

[8] Chu, Y. (2014), "Credit Constraints, Inelastic Supply, and the Housing Boom," Review of Economic Dynamics, 17(1), 52-69.

[9] Favilukis, J., S. Ludvigson and S. Van Nieuwerburgh (2013), "The Macroeconomic Effects of Housing Wealth, Housing Finance, and Limited Risk-Sharing in General Equilibrium," Working Paper.

[10] Fernandez-Villaverde, J. and D. Krueger (2011), "Consumption and Saving over the Life Cycle: How Important are Consumer Durables?" Macroeconomic Dynamics, 15(5), 725770 .

[11] Gabaix, X. (2012), "Variable Rare Disasters: An Exactly Solved Framework for Ten Puzzles in Macro-Finance," Quarterly Journal of Economics, 127(2), 645-700.

[12] Gertler, M. and P. Karadi (2011), "A Model of Unconventional Monetary Policy," Journal of Monetary Economics, 58(1), 17-34.

[13] Glover A., J. Heathcote, D. Krueger and J. Ríos-Rull (2014), "Intergenerational Redistribution in the Great Recession," NBER Working Paper, No. 16924.

[14] Gourio, F. (2008), "Disasters and Recoveries," American Economic Review, 98(2), 68-73.

[15] Gourio, F. (2012), "Disaster Risk and Business Cycles," American Economic Review, $102(6), 2734-2766$.

[16] Harenberg, D. and A. Ludwig (2014), "Social Security and the Interactions Between Aggregate and Idiosyncratic Risk," SAFE Working Paper, No. 59.

[17] Iacoviello, M. (2005), "House Prices, Borrowing Constraints, and Monetary Policy in the Business Cycle," American Economic Review, 95(3), 739-764.

[18] Iacoviello, M. and S. Neri (2010), "Housing Market Spillovers: Evidence from an Estimated DSGE Model," American Economic Journal: Macroeconomics, 2(2), 125-164. 
[19] Iacoviello, M. and M. Pavan (2013), "Housing and Debt over the Life Cycle and over the Business Cycle," Journal of Monetary Economics, 60(2), 221-238.

[20] Krusell, P. and A. Smith (1997), "Income and Wealth Heterogeneity, Portfolio Choice, and Equilibrium Asset Returns," Macroeconomic Dynamics, 1(2), 387-422.

[21] Krusell, P. and A. Smith (1998), "Income and Wealth Heterogeneity in the Macroeconomy," Journal of Political Economy, 106(5), 867-896.

[22] Liu, Z., P. Wang and T. Zha (2013), "Land-price Dynamics and Macroeconomic Fluctuations," Econometrica, 81(3), 1147-1184.

[23] Lucas, R. (1987), Models of Business Cycles, Blackwell, Oxford.

[24] Meh, C., J. Ríos-Rull and Y. Terajima (2010), "Aggregate and Welfare Effects of Redistribution of Wealth under Inflation and Price-level Targeting," Journal of Monetary Economics, 57(6), 637-652.

[25] Pindyck, R. and N. Wang (2013), "The Economic and Policy Consequences of Catastrophes," American Economic Journal: Economic Policy, 5(4), 306-339.

[26] Rietz, T. (1988), "The Equity Risk Premium: A Solution," Journal of Monetary Economics, 22(1), 117-131.

[27] Sommer, K., P. Sullivan and R. Verbrugge (2013), "The Equilibrium Effect of Fundamentals on House Prices and Rents," Journal of Monetary Economics, 60(7), 854-870.

[28] Wachter, J. (2013), "Can Time-Varying Risk of Rare Disasters Explain Aggregate Stock Market Volatility?" Journal of Finance, 68(3), 987-1035.

[29] Yang, F. (2009), "Consumption over the Life Cycle: How Different is Housing?" Review of Economic Dynamics, 12(3), 423-443.

\section{Appendix}

I solve for the recursive competitive equilibrium using the method developed by Krusell and Smith (1997, 1998). First, I specify the grids for the state space $A \times H \times J \times K \times D_{h}$, which consists of three continuous subspaces for financial asset $A$, housing asset $H$ and capital $K$, and two discrete subspaces for age $J$ and disaster shock $D_{h}$. The first three spaces are discretized into equally spaced finite grids, with their lower and upper bounds chosen to be wide enough so that they do not constitute a constraint on the optimization problem. The five-dimensional arrays are then used to store the value and policy functions. 
The algorithm consists of the following steps:

1. Solve for the steady-state equilibrium of the model. Denote $\Phi_{0}$ and $k_{0}$ as the equilibrium distribution and capital stock, respectively.

2. Guess initial coefficients $\left\{\alpha_{i}^{(0)}\left(d_{h}\right)\right\}$ for the approximate laws of motion of capital stock and house prices as specified in (22) and (23).

3. Using the guess taken in step 2, solve the household's optimization problem by backward induction, starting from age $\bar{j}$ with $v(\cdot, \cdot, \bar{j}+1, \cdot, \cdot)=0$. I use linear interpolation to evaluate the value function for values of $k$ not on the grid.

4. Apply the optimal policy functions obtained in step 3 to simulate the dynamics of capital stock and house prices:

(a) Draw a sequence of disaster shocks $\left\{d_{h, t}\right\}_{t=1}^{T}$ by a random number generator.

(b) Since forecasting rules (22) and (23) might not exactly clear the housing market at all dates and states during simulation, I solve an additional optimization problem at each point in time in the simulation:

$\tilde{v}\left(a_{j, t}, h_{j, t}, j, k_{t}, d_{h, t} ; \tilde{p}\right)=\max _{c, h^{\prime}, a^{\prime}}\left\{\begin{array}{c}\left(1-\beta \psi_{j}\right)\left(c^{\nu} h_{j, t}^{1-\nu}\right)^{1-\theta} \\ +\beta \psi_{j} E_{j, t}\left[v\left(a^{\prime}, h^{\prime}, j+1, k_{t+1}, d_{h, t+1}\right)^{1-\gamma}\right]^{\frac{1-\theta}{1-\gamma}}\end{array}\right\}^{\frac{1}{1-\theta}}$

subject to the same constraints in (24) except with an arbitrary house price $\tilde{p}$, but with the continuation value still being the one defined in (24). This results in policy functions $a^{\prime}(. ; \tilde{p})$ and $h^{\prime}(. ; \tilde{p})$. Look for $p_{t}$ until $\sum_{j=1}^{\bar{j}} \mu_{j} h_{j}^{\prime}\left(p_{t}\right)=\bar{h}$, i.e., when the housing market is exactly cleared. I conduct the price search using the secant method. The resulting policy functions $a^{\prime}\left(. ; p_{t}\right)$ and $h^{\prime}\left(. ; p_{t}\right)$ are then used to derive the next-period distribution $\Phi_{t}$ and capital stock $k_{t+1}$.

(c) Keep implementing the above procedure with the provided random draws and get a series $\left\{d_{h, t}, \Phi_{t}, k_{t}, p_{t}\right\}_{t=1}^{T}$ based on the initial distribution $\Phi_{0}$ and capital stock $k_{0}$ obtained in step 1. Drop the first $t_{0}<T$ periods in order to eliminate the influence of the initial distribution and capital stock.

5. Run OLS using the simulated series $\left\{k_{t}, p_{t}\right\}_{t=t_{0}+1}^{T}$ and obtain the new set of forecasting coefficients $\left\{\alpha_{i}^{(1)}\left(d_{h}\right)\right\}$. I separate the simulation points $\left(k_{t}, k_{t+1}\right)$ and $\left(k_{t}, p_{t}\right)$ into two subsamples associated with different realizations of disaster shocks and run OLS separately. If new coefficients are close enough to the previous ones, then the iteration over coefficients is finished. Otherwise, update the coefficients and go back to step 3. I use a linear update formula with $\alpha_{i}^{(0)}\left(d_{h}\right)=(1-\varkappa) \alpha_{i}^{(0)}\left(d_{h}\right)+\varkappa \alpha_{i}^{(1)}\left(d_{h}\right)$ for some $\varkappa \in(0,1)$. 
6. Upon convergence of the coefficients, check the goodness of fit using the $R^{2}$ of the regressions. If the fit is not satisfactory, try different functional forms for the forecasting functions of capital stock and house prices or add more moments of the distribution. 